\title{
Modeling of Gelatinization Time against Water Content for Some Starch Feedstock for Bioethanol Production
}

\author{
OFOEFULE A.U ${ }^{1 *}$, OKORO U $\mathrm{C}^{2}$ and ONUKWULI O D \\ ${ }^{1}$ Biomass Unit, National Center for Energy Research and Development, \\ University of Nigeria, Nsukka. Enugu state, Nigeria \\ ${ }^{2}$ Department of Pure \& Industrial Chemistry, University of Nigeria, \\ Nsukka, Enugu state, Nigeria \\ ${ }^{3}$ Department of Chemical Engineering, NnamdiAzikiwe University, \\ Awka. Anambara state. Nigeria \\ akuzuoo@yahoo.com
}

Received 18 July 2015 / Accepted 31 July 2015

\begin{abstract}
The modeling of gelatinization time against water content of some biomass feedstock viz.; Acha (Digitaria exilis), Finger millet (Eleusine coracana), Tacca (Tacca nvolucrate) and Tigernut (Cyperus esculentus) for bioethanol production was studied. The starches were extracted from the feedstocks by wet and dry milling methods. They were gelatinized at slurry concentrations of $2.0,2.5,3.0$ and $3.5 \mathrm{~mL} / \mathrm{g}$ for acha, slurry concentrations of $2.5,3.0,3.5$ and $4.0 \mathrm{~mL} / \mathrm{g}$ for finger millet, slurry concentrations of 1.0, 2.0, 3.0 and $4.0 \mathrm{~mL} / \mathrm{g}$ for Tacca and slurry concentrations of 3.5, $4.0,4.5$ and $5.0 \mathrm{~mL} / \mathrm{g}$ for tigernut. The starch content of the feedstocks determined the quantity of water used. The gelatinization processes were carried out under different temperature ranges $62{ }^{\circ} \mathrm{C}$ $86^{\circ} \mathrm{C}$ and time $18-59 \mathrm{~min}$. Amylose/amylopectin determinations of the starch feedstocks were also carried out. Modeling was carried out using NLREG 6.3 version a specialized computer programme designed for non-linear regression analysis. Results showed that the acha variant gave the best $\mathrm{R}^{2}$ values $(99.90 \%)$. This was followed by the tigernut starch $\left(\mathrm{R}^{2}=98.70 \%\right)$ and millet starch $\left(\left(\mathrm{R}^{2}=\right.\right.$ $96.10 \%)$. The tacca starch models gave a poorer result $\left(\mathrm{R}^{2}=90.50 \%\right)$. General results indicate that acha starch has the best model within the lowest water content, temperature range and time range amongst the feedstocks studied.
\end{abstract}

Keywords: Gelatinization, modeling, acha, fingermillet, tacca, tigernut, starch

\section{Introduction}

Since the advent of the industrial age, energy need and demand has increased at an astronomical rate and is still increasing by the day. However, conventional energy resources, like fossil fuels, cannot meet the increasing energy demand. The quantities of non-renewable 
(conventional) energy resources are limited and they have a considerable negative environmental impact like increased greenhouse gas emissions. Therefore, one of the challenges for the society is to meet the growing demand for energy for transportation, heating and industrial processes; also to provide raw materials for the industry in a sustainable way and to reduce greenhouse gas emissions ${ }^{1}$. Bioethanol is the principle fuel used as an alternative to gasoline for road transportation. Biological feedstocks that contain appreciable amounts of sugar or materials that can be converted into sugar, such as starch or cellulose can be fermented to produce bioethanol to be used in gasoline engines $^{2,3}$.Gelatinization is a phase transition of starch granules from an ordered to a disordered state during heating with excess water ${ }^{4,5}$. The disordered state consists of melting of orderedregions, both on the crystallite level (inner and surface) and onthe level of amylopectin double-helical order $^{6}$.Starch gelatinization depends on many factors: water content, heating rate, botanical source of starch, processes applied to starch before gelatinization, and amylose/amylopectin content of $\operatorname{starch}^{7}$.Altay and Gunasekaran ${ }^{7}$ studied the gelatinization properties of starch extracted from corn and waxy corn dried at differenttemperatures at various water contents and heating rates. The study revealed that all gelatinization transition temperatures increased with drying temperature and heatingrate. Onset and peak temperatures remained relatively constant, whereas end temperature decreased in the presence of excess water. Coral et al., ${ }^{8}$ studied the influence of the moisture and the grain size on the gelatinization temperature (Tp1) of starch from four industrial maize flours as well as an unprocessed maize. The result showed that for 60,65 , 70 and $75 \%$ of moisture, the endothermic peak temperature increased from 70 to $75^{\circ} \mathrm{C}$ when the moisture increased, and decreased when the grain size increased from 250 to $420 \mu \mathrm{m}$. The properties of acha (Digitaria exilis Kippis.stapf and Digitaria Iburua Kippis. stap f.), finger millet (Eleusine coracana), tigernut (Cyperus esculentus) and tacca ( $\mathrm{T}$. involucrate schum and Thonn) have been described extensively ${ }^{9,10}$. Many of these feedstocks have been identified but lack of data on their chemical composition has limited prospects for their utilization $^{11}$. Most reports on some lesser-known and unconventional crops indicate that they would be good sources of starch for both food and industrial application and many have the potential of broadening the present narrow feedstock base ${ }^{12}$. Starch is widely used as thickener, water binder, emulsion stabilizer, gelling agent in food industries and as bioethanol feedstocks; therefore all information on new sources of starch for industries would be of value in dealing with feedstock availability.This study was undertaken to explore the predictability of gelatinization time with water content for these starches studied.

\section{Experimentals}

The acha grains and finger millet, tacca and tigernut tubers were procured from local markets in Nigeria. The chemicals utilized for the amylose/amylopectin determinations were procured from a local supplier and were used without further purification.

\section{Extraction of starch from acha and finger millet}

This extraction was carried out using a combination of dry and wet milling methods ${ }^{13}$. The acha grains $(3.68 \mathrm{~kg})$ were soaked for three days while the finger millet $(3.65 \mathrm{~kg})$ was threshed several times using a tray to remove stones and other impurities. It was de-hulled using the traditional corn mill grinder. The de-hulled grains were washed with water and soaked for three days after which they were drained. The two starches were then milled with the traditional corn grinder. They were sieved with water using a muslin cloth. The starch-water mixtures were allowed to settle by gravity for some hours. The supernatant was 
decanted. The remaining starch with some quantity of water was poured into a cotton cloth bag, squeezed and pressed severally to expel the remaining water. The resulting starch lumps were broken into small pieces/bits and dried in a solar dryer for a period of five days. It was further dry-milled with an electronic blender to reduce the starch lumps to very fine powdery flour. The starch flour was again sieved with $0.25 \mu \mathrm{m}$ mesh to obtain the finest powdery starch.

\section{Extraction of starch from Tacca and Tigernut}

The extraction of the Tacca starch from this feedstock was carried out by wet milling according to the method of Kunle et al. ${ }^{14}$. Tacca involucrata tubers $(6.1 \mathrm{~kg})$ were washed and peeled to remove the epiderm. The peeled bulks were washed with water, cut and sliced into small pieces. They were milled with mechanical grinder, thereby releasing the starch granules. The resultantpaste was sieved with $0.25 \mathrm{~mm}$ mesh to extract the starch using some quantity of water. The water was removed by allowing the starch to sediment by gravity and decanting of the water. The sedimented starch was squeezed in a muslin cloth bag to remove the water, leaving the starch in cakes. It was then dried by the use of solar dryer for a period of 4 days. The starch which was in caked form was dry milled with an electronic blender, a treatment that reduced it to a very fine powdery starch. The tigernut $(4.5 \mathrm{~kg})$ was threshed to remove the bad ones and other impurities. The nuts were milled to a coarse form. The resulting meal was dried in a solar dryer for a period of seven days to remove the moisture in the nuts. Oil was extracted from the meal in batches with petroleum ether using an extraction column. The de-oiled meal was left in the open for two days to dry off the residual solvent. The de-oiled, solvent-free meal was subsequently milled and sieved concomitantly using a laboratory mill equipped with $0.25 \mu \mathrm{m}$ sieve. This gave a resulting fine powdery starch while leaving the husk/fibre behind ${ }^{15}$.

\section{Gellatinization of the starch samples}

The gelatinization processes were carried out according to the method of Novellie and Shütte $^{16}$. For the acha starch, four sets of $100 \mathrm{~g}$ of acha starch were weighed out. To each of these four sets of $100 \mathrm{~g}$ of the starch was added 200, 250,300 and $350 \mathrm{~mL}$ of distilled water (representing slurry concentrations of $2.0,2.5,3.0$ and $3.5 \mathrm{~mL} / \mathrm{g}$ ) respectively. For the finger millet, four sets of $100 \mathrm{~g}$ of finger millet starch were weighed and added to 250, 300, 350 and $400 \mathrm{~mL}$ of distilled water (representing slurry concentrations of 2.5, 3.0, 3.5 and 4.0 $\mathrm{mL} / \mathrm{g}$ ) respectively. For the tacca, four sets of $100 \mathrm{~g}$ of tacca starch were weighed out and to each of them were added 100, 200, 300 and $400 \mathrm{~mL}$ of distilled water (representing slurry concentrations of 1.0, 2.0, 3.0 and $4.0 \mathrm{~mL} / \mathrm{g}$ ) respectively. For the tigernut, four sets of 100 $\mathrm{g}$ of tigernut starch were weighed and added to $350,400,450$ and $500 \mathrm{~mL}$ of distilled water (representing slurry concentrations of $3.5,4.0,4.5$ and $5.0 \mathrm{~mL} / \mathrm{g}$ ) respectively. Due to the high fibre content of the tigernut starch, less quantities of water could not adequately dissolve the starch.They were heated over water bath till gel formations took place and the gellation temperature noted.

\section{Amylose/amylopectin determination}

For amylose and amylopectin analyses, the four starches were treated with n-hexane to remove any residual lipids present. The method of McReady et al., reported in Adikwu ${ }^{17}$ was used.

\section{Data analysis}

Gelatinization time was modelled against water content for all the starch feedstock using NLREG 6.3 version a specialized computer programme designed for non-linear regression analysis ${ }^{18}$. 


\section{Results and Discussion}

The results of the physicochemical composition of the starch feedstock are shown in Figure 1 with special reference to the amylose/amylopectin results.

Table 1. Amylose/amylopectin ratios of the starch feedstocks

\begin{tabular}{ccccc}
\hline Parameter & Acha & Tacca & Finger millet & Tigernut \\
\hline Amylose/ Amylopectin ratio & $26.5: 73.50$ & $27: 73$ & $24: 76$ & $35.75: 64.25$ \\
\hline
\end{tabular}

Gelatinization time was modelled against water content for all the starch feedstock using NLREG 6.3 version a specialized computer programme designed for non-linear regression analysis. Table 2 gives the values obtained for the parameters that explains the models.

Table 2. Regression parameters for gelatinization time $v s$. water content

\begin{tabular}{cccccccc}
\hline Feedstock & $\mathrm{P}_{0}$ & $\mathrm{P}_{1}$ & $\begin{array}{c}\text { Gel time } \\
(\mathrm{min}) \text { range }\end{array}$ & $\begin{array}{c}\text { Water content } \\
\text { range, } \mathrm{mL} / \mathrm{g}\end{array}$ & $\begin{array}{c}\mathrm{R}^{2} \\
(\%)\end{array}$ & $\mathrm{Ra}^{2}(\%)$ & $\operatorname{Prob}(\mathrm{t})$ \\
\hline Acha & 3.00 & 0.08 & $18-29$ & $2.0-3.5$ & 99.90 & 92.86 & 0.84 \\
Millet & 8.80 & 0.036 & $18-24$ & $2.5-4.0$ & 96.10 & 85.77 & 0.73 \\
Tacca & 21.00 & 0.008 & $21-24$ & $1.0-4.0$ & 90.50 & 80.00 & 0.005 \\
Tigernut & -4.10 & 0.12 & $40-53$ & $3.5-5.0$ & 98.70 & 89.00 & 0.73 \\
\hline
\end{tabular}

The relationship of gelatinization time and water content is given by the equation 1 below:

$$
\mathrm{GT}=\mathrm{P}_{0} \mathrm{x}^{2}+\mathrm{P}_{1} \mathrm{x}+\mathrm{P}_{2}
$$

Where;

$$
\begin{array}{ll}
\mathrm{GT} & =\text { Gelatinization time }(\mathrm{min}) \\
\mathrm{x} & =\text { Water content }(\mathrm{mL} / \mathrm{g}) \\
\mathrm{P}_{0}, \mathrm{P}_{1} & =\text { Constants }(\text { Table } 2) \\
\mathrm{P}_{2} & =\text { Slope }
\end{array}
$$

This relationship is graphically represented in Figures 1 and 2. The positive sign implies increase of gel formation with time. There was positive correlation between the factors (water content and gelatinization time) implying that increase in gel formation was a function of time and a first order kinetics. The rate of gelatinization and temperature was directly proportional to water quantity. A good model is determined by the $\mathrm{R}^{2}$ and $\mathrm{Ra}^{2}$ values. These represent the proportion of variance and coefficient of multiple determinations respectively. The amount of variants explained by the model $\left(\mathrm{R}^{2}\right)$ also shows the level to which other variants can be predicted by the model. The acha variant gave the best $R^{2}$ values indicating that other water contents not utilized in the experiment can be predicted using the equation (1) above.
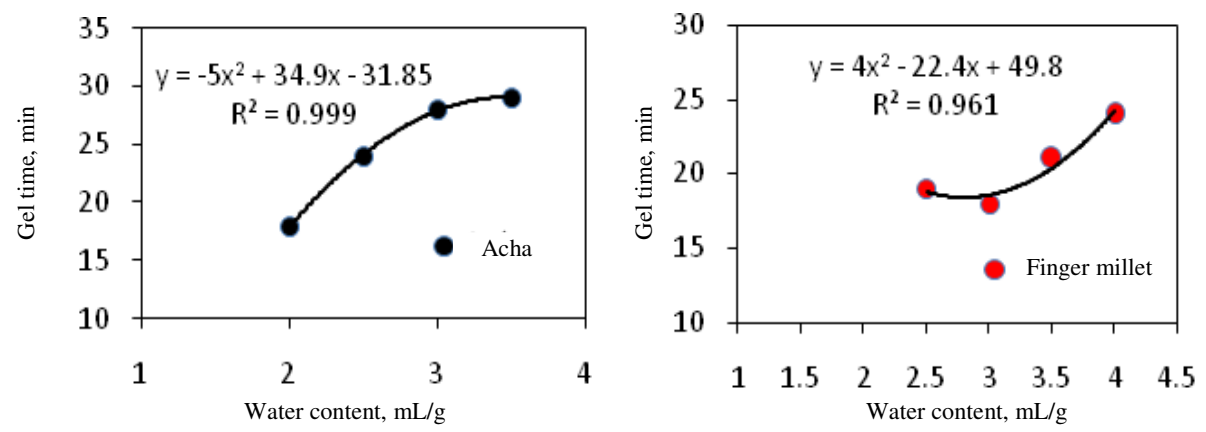

Figure 1. Variation of gelatinization time with water content for acha and finger millet 

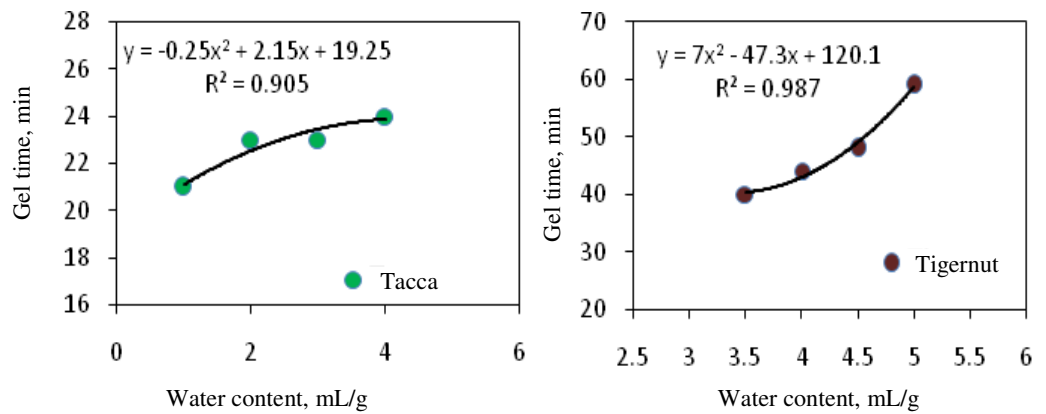

Figure 2. Variation of gelatinization time with water content for tacca and tigernut.

This was followed by the tigernut starch. The tacca starch models gave a poorer result (a good model is expected to have $\mathrm{R}^{2}$ values in the range of $95-99 \%$ ). This may be accounted for by the incremental levels of water content in the tacca which did not follow the trend of the other variants (the incremental water content was $1.0 \mathrm{~mL} / \mathrm{g}$ while the others where $0.5 \mathrm{~mL} / \mathrm{g}$ ).

The Prob(t) values represents the probability that replacing the parameters with zero would not alter the correlation and as a result should be very low (0-0.9). The Prob(t) for all the starch variants were low, however, that of tacca starch was the lowest, while that for finger millet and tigernut were not sufficiently low but are however acceptable and does not affect the models. It was observed experimentally that the texture of the gels formed for the starch variants were affected by the water volume. The thickness of gel decreased as the water content increased provided all other conditions were kept constant. Again, the rate of cooling of the respective gelatinized starches followed the same trend. On cooling, the rates of retrogradation (i.e. the process by which gelatinized starch gradually begins to re-organize its components to return to its former molecular structure while being cooled) for the starch feedstocks differed and decreased in the order; tigernut $>$ tacca $>$ acha $>$ finger millet. This may be explained with the amylose/amylopectin ratio of the starch samples (Table 1). The higher the amylose contents of a starch the greater the effectiveness of the retrogradation process $^{19}$. In the same vein, the degree of gelatinization is proportional to the amount of amylose in the starch. Higher amylose contents leads to lower degree of gelatinization and vice vers $a^{20}$. The result of the amylose/amylopectin contents of the different starches (Table 1) shows that finger millet had the least amylose content, followed by the acha, then the tacca and the highest amylose content was from the tigernut. This explains why the retrogradation of the tigernut was highest and the degree of gelatinization lowest.

\section{Conclusion}

The study has shown the modelling of gelatinization time against water content for acha, fingermillet, tigernut and tacca starches. General results show that the acha starch gave the highest predictability of gelatinization time with water content. This was followed by tigernut starch, while the tacca gave the poorest result.

\section{References}

1. Mojović L, Pejin D, Grujić O, Markov S, Pejin J, Rakin M,Vukašinović M, Nikolić S and Savić D.,C I, C E Q, 2009, 15 (4), 211-226.

2. Balat $\mathrm{M}$ and Balat H, Appl Energy, 2009, 86(11), 2273-2282; DOI:10.1016/j.apenergy.2009.03.015

3. Baras J, Gaćeša S and Pejin D, Chem Ind., 2002, 56, 89-105 
4. Chaiwanichsiri S, Ohnishi S, Suzuki T, Takai R and Miyawaki O, J Sci Food Agric., 2001, 81(15), 1586-1591; DOI:10.1002/jsfa.983

5. Freitas A, Paula R C, Feitosa J P A, Rocha S and Sierakowski M R, Carbohydr Polym., 2004, 55(1), 3-8; DOI:10.1016/S0144-8617(03)00142-5

6. Randzio S L, Flis-Kabulska I and Grolier J P E, Macromolecules, 2002, 35(23), 88528859; DOI:10.1021/ma011213r

7. Altay F and Gunasekaran F S. J Agric Food Chem., 2006, 54(12), 4235-4245; DOI:10.1021/jf0527089

8. Coral D F, Pineda-G'Omez P, Rosales-Rivera A and Rodriguez-Garcia M E, J Phys: Conf Ser., 2009, 167(1), 012057.

9. Ofoefule A U, Okoro U C and Onukwuli O D, Chem Sci Trans., 2015, 4(2), 331-336; DOI: $10.7598 /$ cst2015.986

10. Ofoefule A U, Okoro U C and Onukwuli O D, Der Pharma Chemica, 2015, 7(6), 324-329.

11. Vijayakumari K, Siddhuraju P and Janardhanan K, Food Chem., 1994, 50(3), 285288; DOI:10.1016/0308-8146(94)90134-1

12. National Academy of Sciences.Under exploited tropical plant with promising economic value. Report of Ad-hoc panel of the Advisory Committee on Technology Innovation. 1975.

13. Takeda C, Takeda Y and Hizukuri S. Physicochemical properties of lily starch, Cereal Chem., 1983, 60(3), 212-216.

14. Kunle O O, Ibrahim Y E, Emeje M O, Shaba S and Kunle Y, Starch/Stärke, 2003, 55(7), 319-325; DOI:10.1002/star.200390067

15. Oderinde R A and Tahir O A, Nig J Sci., 1988, 22, 70-73.

16. Novellie L and Schütte. R J. J Sci Food Agric., 1961, 12(8), 552-559; DOI:10.1002/jsfa.2740120804

17. Adikwu M U, Nig J Nat Prod Med., 1998, 2, 54-56; DOI:10.4314/njnpm.v2i1.11786

18. Ofoefule A U, Uzodinma E O and Anyanwu C N, Trends Appl Sci Res., 2010, 5(1), 39-47.

19. Fredriksson H, Silverio J, Andersson R, Elliasson A C and Aman P, Carbohydr Poym., 1998, 35, 119-134.

20. Yuan R C, Thompson D B and Boyer C D, Cereal Chem., 1993, 70(1), 81-89. 